\title{
A “inclusão digital indígena” na Sociedade da Informação
}

\author{
Alejandra Aguilar Pinto
}

\section{Resumo}

Este documento faz parte da atual pesquisa de doutorado, intitulada A Identidade/Diversidade Cultural no ciberespaço: práticas informacionais e de inclusão digital nas comunidades indígenas, o caso dos Kariri-Xocó e Pankararus.A metodologia empregada consistiu de uma pesquisa documental, entrevistas a especialistas, assim como uma visita a campo para conhecer a realidade da "inclusão digital indígena" em duas comunidades. A pesquisa deu como resultado que a inclusão digital indígena começou como uma política pública, mas logo o setor privado começou a participar com medidas deste tipo.Por outro lado, os povos indígenas apresentaram um entusiasmo e uma vontade de aprender, porém foram críticos e questionadores a estes programas, sobretudo os governamentais, por a sua lentidão, burocracia e escassez de recursos.

Palavras-chave: Inclusão digital. Povos indígenas. Sociedade da informação.

Título: La "inclusión digital indígena" en la Sociedad de la Información

\section{Resumen}

Este documento es parte de la actual investigación de doctorado titulada La identidad/Diversidad Cultural en el ciberespacio: prácticas informacionales y de inclusión digital en dos comunidades indígenas: el caso de los kariri-xocó e pankararus. La metodología empleada consistió de una investigación documental, entrevistas a expertos y estudio de campo para conocer en terreno la realidad de estas comunidades. La investigación tuvo como resultado que la inclusión digital de los pueblos indígenas comenzó como una política pública, pero después el sector privado comenzó a participar. Los pueblos indígenas demostraron entusiasmo y ganas de aprender, pero además han sido críticos y han cuestionado estos programas, especialmente del gobierno, por su lentitud, burocracia e falta de recursos.

Palabras clave: Pueblos indígenas. Sociedad de la información. Inclusión digital. Sector privado. Políticas públicas.

\footnotetext{
* Mestre em Ciência de Informação (C.I). Atualmente Doutoranda no Programa de Pós-graduação em Ciência de Informação-PPGCI, Linha de pesquisa: Comunicação da Informação. E-mail: ale.unb@gmail.com
} 
Title: The "digital inclusion indigenous" in the Information Society

\begin{abstract}
This text is part of a current doctoral research entitled The Identity / Cultural Diversity in Cyberspace: informational and practice of digital inclusion in the Indian communities, the case of Kariri-Xoco and Pankararus. The methodology employed consisted of documentary research, interviews with experts and a visit to perceive the reality of indigenous peoples concerning digital inclusion in two communities. Research results show that indigenous people began digital inclusion as result of public policies, but soon the private sector got involved. Furthermore, Indigenous peoples had enthusiasm and willingness to learn, but were critical and questioned these programs, especially the government, for its slowness, bureaucracy and lack of resources.
\end{abstract}

Keywords: Indigenous peoples. Information society. Digital inclusion. Public policies. Private sector.

\title{
1 Introdução
}

Os povos nativos são um segmento da sociedade que sempre ficaram excluídos no acesso ao conhecimento, desde o surgimento das telecomunicações, as redes eletrônicas e sua convergência nas tecnologias de informação e comunicação (TICs), estas novas ferramentas causaram outro impacto nas comunidades indígenas, o que poderia considerar-se positivo ou negativo dependendo da possibilidade de acesso ou uso.Os primeiros computadores acessíveis aos indígenas, revelaram um desconhecimento sobre seu uso, logo as TICs através de sistemas de redes, causaram outra exclusão, pois estas ferramentas implicavam uma conexãovinculação, mas a realidade indígena em geral carecia união, existindo alguns fatos isolados de grupos étnicos com conexão simples a redes com uma difusão dos seus conteúdos nos circuitos virtuais (sobretudo de países do Norte).

A rede Internet constitui uma massa de informação que apresenta fundamentalmente um caráter etnocêntrico, que não considera as diferenças culturais e identidades étnicas das culturas minoritárias. Os povos indígenas têm tido um impacto desta mídia que condiciona seu acesso/uso pelo conhecimento de comandos e estratégias de busca, assim como pela elaboração de conteúdos digitais. Até que ponto as práticas informacionais estão sendo feitas pelos povos indígenas é uma questão a indagar.

O objetivo principal deste documento é dar a conhecer as medidas governamentais nacionais privadas e públicas de inclusão digital deste segmento, procurando estabelecer os impactos que têm tido neles, desde o ponto de vista da criação, uso e comunicação de suas 
informações.

\section{A inclusão digital (I.D.) uma forma de integração e participação da comunidade na Sociedade da Informação}

A Inclusão digital é um termo surgido recentemente, ante o intensivo desenvolvimento das TICs, sobretudo da tecnologia digital on-line, o que tem desafiado aos usuários a dominar uma serie de informações/conhecimentos sobre o uso, tanto de hardware, software e conteúdos veiculados pelas redes eletrônicas. Contudo, o principal razão desta nova medida ou programa pró-acesso/uso, é a marginalização de grandes camadas da população que por carecer das condições mínimas de bem- estar, não têm pelo geral um acesso mínimo assegurado às tecnologias de informação, que são elementos chaves para a formação integral do ser humano, no que respeita ao acesso e uso das informações.

\subsection{Algumas aproximações conceituais}

O desenvolvimento das indústrias culturais (Cinema, rádio, televisão, imprensa) e o acentuado avanço das tecnologias de informação e comunicação, desde a escrita, informática, telecomunicações, causaram diversos impactos na sociedade, respeito ao controle, armazenamento, criação, acesso/uso e difusão das informações por elas veiculadas; em um começo o registro de informações permitiram a conservação e logo uma ampla difusão com as mídias eletrônicas e digitais, mas com o crescimento exponencial das informações o impacto foi maior, sobretudo na seleção e "compreensão" das informações.

A problema social e econômico de acesso ás TICs se solucionou em parte, com os chamados programas de inclusão digital, ficando o desafio de ensinar aos usuário no uso criativo e produtivo das informações digitais das redes, isto é, a criação de conteúdos. As TICs têm como característica principal permitir ao usuário consumidor não ter um papel "passivo" na recepção de informações, podendo ser um agente ativo na produção e veiculação de informações próprias, como emissor em conexão com as mídias digitais.

A inclusão digital é uma medida de tipo social, um processo que primeiramente pretende fazer parte a àquela parcela da população que não tem nenhum tipo de acesso as TICS, estimulando, sobretudo o uso eficiente e eficaz de ferramentas 
tecnológicas para o desenvolvimento de conteúdos, estas medidas em geral são efetuadas por entidade de governo em parceria com empresas privadas.

Pierre Lévy (1999) nos indica que as tecnologias virtuais como o ciberespaço não são em si as causantes de exclusão social, mas a quantidade e velocidade da informação que estas tecnologias processam podem levar a uma marginalização do ótimo e eficaz uso:

Segundo este autor a Cibercultura traz consigo o problema da questão da exclusão. Para ele o crescimento do Ciberespaço provoca uma exclusão social: "A cibercultura provoca exclusões?, é, evidentemente uma pergunta central em uma sociedade mundial na qual a exclusão (ou seja, a forma contemporânea, de injustiça social) é uma das principais doenças” (1999, p.235)

LÉVY acredita que as tecnologias e a economia não são, contudo, os principais fatores de exclusão:

\begin{abstract}
"Acesso para todos sim! Mas não se deve entender por isso um 'acesso ao equipamento, a simples conexão técnica que, em pouco tempo, estará de toda forma muito barata (...) Devemos antes entender um acesso de todos aos processos de inteligência coletiva, quer dizer, ao ciberespaço como sistema aberto de autocartografia dinâmica do real, de expressão das singularidades, de elaboração dos problemas, de confecção do laço social pela aprendizagem recíproca, e de livre navegação nos saberes. A perspectiva aqui traçada não incita de forma alguma a deixar o território para perder-se no 'virtual', nem a que um deles 'imite' o outro, mas antes a utilizar o virtual para habitar ainda melhor o território, para tornar-se seu cidadão por inteiro" (LÉVY, 1999, p.196)
\end{abstract}

A inclusão digital em geral é vista como uma forma de combater a exclusão digital, nas suas mais diversas formas ou graus. "A inclusão digital é vista por muitos como um importante meio de integração das classes menos favorecidas, sendo um fator de auxílio para a inclusão social das mesmas" (COSTA, L. 2005, p. 5).

"A inclusão digital representa um canal privilegiado para equalização de oportunidades da nossa desigual sociedade em plena era do conhecimento" (NERI, 2003, p.6)

A inclusão digital pode ser uma medida estratégica de integração de setores marginados da sociedade da informação, para Bernardo Sorj (2003, p.14) "embora aceitemos que as novas tecnologias não sejam uma panacéia para os problemas da desigualdade elas constituem hoje uma das condições fundamentais de integração na vida social”. Segundo Sorj (2003) o combate à exclusão digital deve ser articulado com outras políticas de luta contra as diversas desigualdades sociais.

Para Rondelli (2003) a "inclusão digital esta relacionada à aprendizagem necessária ao individuo para circular e interagir no mundo das mídias digitais, como consumidor e como 
produtor de seus conteúdos e processos. Assim, estabelece-se uma relação intrínseca entre acesso/uso. È a partir do uso que as pessoas fazem das informações que se podem distinguir níveis ou tipos de inclusão digital".

Esta mesma autora destinge etapas na inclusão digital indicando quatro passos importantes, sendo elas: o ensino (para a autora possibilitar apenas o simples acesso não adianta); oportunidades de emprego dos suportes técnicos digitais na vida cotidiana e no trabalho; necessidade de políticas públicas para inclusão e a exploração dos potenciais meios digitais.

Castells (2003, apud LAIPELT, MOURA, CAREGNATO, 2005, p. 286), por sua vez, defende que a capacidade educativa e cultural de utilizar a Internet, é um segundo elemento de divisão digital, muito mais difícil de solucionar que a simples ausência de conectividade técnica. Para o autor, não saber onde encontrar a informação, como buscá-la, processá-la e transformá-la em conhecimento especifico para aquilo que se quer fazer, é o que determina a divisão digital, para ele a capacidade de aprender a aprender, e saber o que fazer com o que se aprende é uma capacidade socialmente desigual, associada à origem social e familiar, bem como ao nível cultural e educacional. Portanto, para superar a divisão digital é necessário superar também a desigualdade social.

Outros autores relacionam inclusão digital com alfabetização digital, para Young (2006, p.97)

\footnotetext{
"a inclusão digital significa capacitar as pessoas para o uso efetivo dos recursos tecnológicos de maneira plena, como ferramentas que contribuem para o desenvolvimento social, econômico, intelectual e político do cidadão. È a aprendizagem necessária ao individuo para interagir no mundo das mídias digitais, podendo não apenas saber aonde encontrar a informação, mas também qualificá-la e torná-la útil para seu dia a dia. Se esta falando de agregar às habilidades fundamentais e imprescindíveis de ler /escrever aquelas de lidar com médios eletrônicos-conectarem-se me rede, realizar pesquisa, executar tarefas rotineiras".
}

Como se pode apreciar a inclusão digital tem uma dimensão eminentemente formativa, tentando combater o novo tipo de brecha digital, por alguns denominada de brecha informativa ou cognitiva.

Cabeda (apud GALVÃO 2006, p.24) destaca a vinculação e relação da inclusão digital/alfabetização digital com uma política pública, o que demonstra algumas ações práticas de cidadania em nível médio sendo implementadas através de tele-centros, infocentros e cíbercafes, Assim a Inclusão digital pode ter diferentes focos ou metas de ação, sendo o principal desafio formar cidadãos com a capacidade de habilidade de criar e encontrar conteúdos no universo digital. Desenvolver esta autonomia implica fomentar desde o mais 
cedo possível o acesso a estas ferramentas, para que eles se apropriem, no sentido de dominar o conhecimento técnico de hardware, para logo fazer uso e determinar em que aspectos a informação recuperada/criada será utilizada. O principal desafio da inclusão digital é justamente fazer das tecnologias um instrumento de informação habitual no ambiente do usuário, que ele se dê conta que estas são chaves para fazer frente às novas demandas laborais e de competitividade que e o mundo do trabalho exige. Estes instrumentos devem passar a ser, como é agora a televisão, num futuro próximo, meios que estejam no cotidiano das pessoas. Porém, por enquanto a meta é que a maioria das pessoas comecem a dominar o conhecimento do equipamento, sua estrutura, a qual não tem nenhum secreto, para logo ver que estas ferramentas são só as vias pelas quais circula e se armazena o insumo principal sobre o qual ele vai criar conhecimento, isto é, a Informação.

\section{Políticas ou programas de inclusão digital (I.D.) na América Latina, o caso do Brasil}

O novo cenário global mundial tem motivado diferentes medidas nacionais para não ficar à margem dos avanços constantes nas tecnologias de informação e comunicação, que têm levado a uma maior vinculação e dependência entre as economias do norte e do sul.

Assim no caso do Brasil o marco oficial de inicio de entrada na Sociedade de informação, foi o Programa Sociedade de Informação, que por meio do Decreto 3.294 de 15 de dezembro de 1999 que teve por objetivo “(...) integrar, coordenar e fomentar ações para a utilização de tecnologias de informação e comunicação, de forma a contribuir para que a economia do país tenha condições de competir no mundo global e, ao mesmo tempo, contribuir para a inclusão social de todos os brasileiros na nova sociedade". (MINISTERIO DE PLANEJAMENTO, ORÇAMENTO E GESTÃO, 2004)

No Brasil as políticas públicas de I.D. diferem de um Estado a outro, com a finalidade de integrar a todos os programas, existentes no governo federal, estadual e municipal, o secretario executivo do Ministério das Comunicações Paulo Lustosa, indicou em julho do 2004 que seria criado o Modelo Brasileiro de Inclusão Digital, numa tentativa de otimizar as ações e evitar a duplicidade de projetos.

A democratização do acesso à tecnologia tem sido assumida em diversos graus pelos governos nacionais de turno, isto é, tem sido até agora medidas públicas ligadas a partidos políticos. Porém, iniciativas da área privada, da sociedade civil, empresas transnacionais e 
organismos internacionais, já têm criado algumas medidas de inclusão digital.

No caso do Brasil, a principal instituição que comandou a inclusão digital no começo, foi o Instituto Nacional de Tecnologia (ITI), vinculado à Casa Civil que durante muito tempo teve um atuar passivo, além de sua função principal de ser o implementador e guardião da certificação digital oficial do Brasil, sob a direção de Sergio Amadeu da Silveira, o ITI começou a participar da articulação de várias iniciativas para democratizar as TICs e para disseminação do software livre na administração pública e na sociedade como um todo, inclusive por médio do Programa PC Conectado, cujo lançamento aconteceu em Junho 2005. Responsável pela coordenação do Comitê de Software Livre do Governo eletrônico, o ITI incluiu o tema na agenda de políticas públicas do país, provocou debate em torno de por que e quando usar as plataformas livres no lugar de soluções proprietárias; contribuiu junto a outros órgãos do governo, sob a coordenação da Secretaria de Comunicação de Governo e Gestão estratégica (SECOM), para a formulação do Projeto Casa Brasil, e participou ativamente dos debates para a construção da posição brasileira para a Cúpula da Sociedade da Informação, que aconteceu na Tunísia em novembro de 2005.

Por outra parte, há que salientar que o Programa de Inclusão Digital do governo também articula iniciativas de vários órgãos públicos, como são os ministérios, além da Casa Civil e da SECOM: Ministérios das Comunicações, com o Governo Eletrônico Serviço de Atendimento ao Cidadão (GESAC); Ministério do Planejamento, por meio de ações da Secretaria logística e Tecnologia da Informação; Ministérios da Ciência e Tecnologia, através das Secretarias de Inclusão Social e Informática; Ministérios do Desenvolvimento, com sua rede de telecentros de negócios; e apropria Presidência da República, que coordena, por meio de sua assessoria especial, o programa PC Conectado.

No final de 2003 mais de 12 milhões de usuários foram beneficiados com projetos de I.D. por todo o Brasil, ou seja, 7\% da população estimada em 170 milhões, mas estes projetos a maior parte acontecem no Sudeste, o que revela a importância de políticas públicas responsáveis para que haja uma democratização dos meios, considerando também as outras regiões do Brasil. ${ }^{1}$

"O Plano Plurianual do governo federal prevê a expansão do numero de telecentros comunitários, (...) a meta é chegar a 6 mil em todo o pais até 2007”2.

A divulgação da construção do Modelo Brasileiro de I.D. e das metas governamentais

\footnotetext{
${ }^{1}$ www.idbrasil.gov.br/noticias/News_Item.2004-07-13.2831 Acesso em: 17/07/04 2004.

${ }^{2}$ www.idbrasil.gov.br/noticias/News_Item.2004-06-28.5853 Acesso em: 17/07/04.
} 
do Plano Plurianual mostra que o governo federal está preocupado em alterar o quadro atual da exclusão digital. Para Silveira (2003, p.29-30) a importância da inclusão digital como política pública esta consolidada por quatro pressupostos:

\begin{abstract}
"Primeiro, o reconhecimento de que a exclusão digital amplia a miséria e dificulta o desenvolvimento humano, local e nacional. A exclusão digital não representa uma mera conseqüência da pobreza crônica. Torna-se fator de congelamento da condição de miséria e grande distanciamento em relação às sociedades ricas. Segundo, a constatação de que o mercado não irá incluir na era da informação os estratos pobres e desprovidos de dinheiro. A própria alfabetização e a escolarização da população não seriam maciças se não fosse pela transformação da educação em política pública e gratuita. A alfabetização digital e formação básica de viver na cibercultura também dependerão da ação do Estado para serem amplas ou universalistas. Terceiro, a velocidade da inclusão é decisiva para que a sociedade tenha sujeitos e quadros em números suficientes para aproveitar as brechas de desenvolvimento no contexto da mundialização de trocas desiguais e, também, para adquirir capacidade de gerar inovações. Quarto, a aceitação de que a liberdade de expressão e o direito de se comunicar seriam uma falácia se fossem destinados apenas à minoria que tem acesso à comunicação em rede. Hoje o direito à comunicação é sinônimo de direito à comunicação mediada por computador, portanto, trata-se de uma questão de cidadania".
\end{abstract}

Uma das principais ações criadas pelo governo para combater a exclusão e promover a democratização foi o FUST -Fundo de Universalização dos Serviços de Telecomunicações, através da lei de número 9.998 do dia 17 de agosto de 2000. O programa tem por finalidade proporcionar recursos destinados a cobrir a universalização de serviços de telecomunicações, uma criação do Ministério das Comunicações numa ação conjunta com a Agencia Nacional de Telecomunicações (ANATEL).

“Um projeto (o $\mathrm{FUST}^{3}$ ) ambicioso que instalará computadores em 12 mil escolas médias, alcançando 6,5 milhões de estudantes, 280 mil professores e 5.000 municípios". (NERI, 2003 apud COSTA, L. 2005, p.11)

E outra das medidas de base nos programas de inclusão do governo é adoção do software livre, este pode ser definido como "aquele software disponível com a permissão par qualquer um usá-lo, copiá-lo e distribuí-lo, seja na sua forma original ou com modificações, seja gratuitamente ou com custo.” (COSTA, L. 2005, p.11)

Está em curso um debate a nível mundial sobre o uso deste tipo de software, dado os custos dos programas comercializados pelas grandes empresas informáticas e seu monopólio. Existe um movimento que prega a colaboração e o compartilhamento do conhecimento. "É

\footnotetext{
${ }^{3}$ Fundo de Universalização dos Serviços de Telecomunicações.
} 
uma revolução feita em regime colaborativo de descentralizado, sem um partido político no comando, mas com pedaços de código em computadores diferentes espalhados pelo planeta, comandados por gente que trabalha não para ficar rica, mas querendo o bem comum" (VIANNA, 2004 apud COSTA, L. 2005, p.12)

\begin{abstract}
“As políticas voluntaristas de luta contra as desigualdades e a exclusão devem visar o ganho em autonomia das pessoas ou grupos envolvidos. Devem, em contrapartida, evitar o surgimento de novas dependências criadas pelo consumo de informações ou de serviços comunicação concebidos e produzidos em uma óptica puramente comercial ou imperial” (LÉVY, 1999, p.238)
\end{abstract}

Cabe perguntar-se nos cursos de alfabetização digital o que se ensina é algo determinado por padrões forâneos, tanto de software e hardware ou bem se orienta no uso de programas de qualquer plataforma informática, para ter cidadãos autônomos que podem esta aptos para navegar ou usar qualquer meio.

\title{
3.1. Medidas governamentais de acesso/ uso das TICs na sociedade brasileira
}

A continuação se descreve brevemente alguns projetos de inclusão digital de caráter amplo genérico, como é programa Casa Brasil e outros mais especializados como do Ministério da Cultura com o programa Cultura Viva e seus Pontos de Cultura. Fez-se a escolha desses por estar mais vinculado com a sociedade como um todo, podendo atingir outros segmentos ou integrantes da comunidade, como seriam os povos indígenas.

Logo descrevesse com mais detalhes as iniciativas públicas de inclusão digital que têm passado a considerar as culturas indígenas.

\section{Casa Brasil.(Casa Civil-ITI)}

A principal ação de governo é o denominado programa Casa Brasil, idealizado inicialmente para unificar as iniciativas de inclusão digital e ampliá-las. Este programa "é um conjunto de módulos que têm em seu coração o telecentro, ou seja, um módulo onde as ferramentas de tecnologias de informação, incluindo o acesso à Internet, são utilizadas não só para dar ao jovem as noções básicas de como usar o computador, de navegar na Internet, como usar o conhecimento que está disponível na rede e como aprender a compartilhá-lo com outros usuários da rede". (AQUINO, 2005, p.12) 


\section{Cultura Viva. (Ministério de Cultura)}

Outro programa destacado é o caso do programa do Ministério da Cultura, através do seu programa Cultura Viva, este tem um enfoque principalmente cultural. Cultura Viva é o Programa Nacional de Cultura, Educação e Cidadania, que pretende estimular o uso das tecnologias da informação para criar uma rede multimídia de produtores culturais. Seus articuladores recorrem uma frase do ministro Gilberto Gil para explicar o que é o projeto: um do-in antropológico, uma massagem em pontos vitais do corpo cultural do país, para fazer com que a energia circule entre eles. Os Pontos de Cultura, principal iniciativa do Cultura Viva, foram assim denominados, graças a essa metáfora. As entidades que vão abrigar os pontos recebem dinheiro, equipamentos e capacitação para fazer o que há que fazer e que os torna pontos vitais: reunir brasileiros e produzir cultura. Neste programa algumas aldeias indígenas têm-se inserido.

“O projeto faz parte da terceira geração de inclusão digital, que pressupõe a alfabetização dos cidadãos em uma das cinco línguas da era digital - texto, imagem, vídeo, sons e linguagens de desenvolvimento de software - e uma política de acesso público à banda larga" explica Cláudio Prado, coordenador da Cultura Digital". (A Rede , 2005, p.15)

\section{GESAC-(Ministério das Comunicações).}

É a iniciativa mais ampla de inclusão digital-social governamental, seus antecedentes se encontram no governo anterior que tinha outro foco. Da sua concepção inicial, no governo anterior, quando foi pensado como quiosques eletrônicos, como uma única maquina, para acesso gratuito apenas a conteúdos.gov, o GESAC avançou muito. O grande mérito do atual governo, na avaliação não só de Albuquerque (um dos primeiros diretores de inclusão digital do Ministério das Comunicações), como de especialistas de inclusão digital, foi ter revisto o projeto inicial: o foco do atendimento mudou, priorizando escolas com laboratórios de informática sem conexão a internet, em primeiro lugar, unidades militares de fronteira (más não só) e projetos localizados em regiões de difícil acesso. Além disso, a velocidade de conexão foi ampliada para $256 \mathrm{kbps}$, o período de cobertura de contrato estendido de 16 para 22 meses, a capacidade alocada no satélite passou para 50MHz e o software livre foi adotado como plataforma. Mais ferramentas de controle e serviços foram exigidas no datacenter.(XAVIER, F.; DIAS, Lia R., 2005, p.18-19).

Como já se indicou em parte, este programa de inclusão digital é quem mais têm conseguido incluir a uma ampla variedade de população, considerado, sobretudo as 
localidades de difícil de acesso. Um programa em certa forma diferenciado, que passou a considerar as particularidades, diferenças da comunidade brasileira.Em muitos casos o GESAC é o único canal de comunicação da população.

\subsection{Experiências de inclusão digital estadual comunitária}

A apropriação comunitária das conexões estabelecidas com antena do GESAC varia. Pode servir para complementar a educação básica, como na Escola indígena Baniwa Coripaco Pamaáli, na região amazônica, ou para fomentar arranjos produtivos locais, negócios e cooperativo - caso de um grupo de pescadores de Cabo Frio (RJ). Ou para as duas coisas simultaneamente, como aconteceu e Mineiros (GO), onde o laboratório de informática da escola foi instalado em um centro de convivência e fortaleceu o trabalho de uma comunidade de quilombolas com ervas medicinais. Em telecentros, como aquele criado em parceria com a Eletronorte junto ao rio Xingu, também pode, simplesmente, servir para ampliar o repertorio geral das pessoas e fomentar idéias para a solução de problemas locais.

\subsubsection{A inclusão digital indígena no Brasil}

A "inclusão digital dos indígenas" começou e se têm desenvolvido fundamentalmente através de parcerias entre o setor público e privado; os programas de governo se têm incorporado como uma forma de fazer inclusão social e digital, daqueles setores por muito tempo foram marginalizados no acesso/uso da informação e as tecnologias. Esta inclusão só começou recentemente, e os fatos hão demonstrado que para prosperar e fortalecer-se no tempo, papel chave o têm tido várias instituições governamentais, principalmente ministérios, mas em aliança com organizações não governamentias e da sociedade civil.

As etnias do Brasil nos programas sociais não foram consideradas uma prioridade, mas em forma desigual e discriminatória, o qual levou a que os mesmos indígenas se organizarem em associações, para demandar a sua participação ou inclusão nas políticas, agora de tipo digital.

Um destes casos é o povo Ashaninka no estado do Acre, que estão conectados á rede Internet desde 2003, este foi o segundo ponto da Rede Povos da Floresta. Hoje esta organização é uma organização não governamental (ONG), uma rede que nasceu de uma 
parceria do Comitê para Democratização da Informática (CDI) com a Star One, empresa de satélite da Embratel, e é apoiada pela Comissão Satélite do Acre. Antes desta etnia, estiveram os Yawanawa também em território acreano, com o primeiro ponto do projeto.A Rede Povos da Floresta tem cinco "pontos indígenas" funcionando e durante o ano 2006 deveriam ser instalados novos pontos.

Outro projeto, é a Rede Floresta Topawa Ka'á (rede florestas no dialeto parakanã), patrocinado pela Eletronorte, com quatro pontos em operação, gerido pelos próprios indígenas.

Outro caso é mantido pela ONG Instituto Sócio-Ambiental (ISA), o telecentro dos Baniwa, tribo da Terra Indigena do Alto Rio Negro. "São quase cem alunos na escola indígena que têm computador e internet. Aproveitamos o que a rede nos traz de bom, informações de plantas, pesca, ecologia, tudo que for útil para a comunidade", indica André Fernando Baniwa, escolhido pelo seu povo como emissário junto ao homem branco. André Fernando mora em São Gabriel, sendo vicepresidente da Federação das Organizações Indígenas do Rio Negro (FOIRN). "Hoje só temos dois computadores, mas todo mundo usa. A partir de 13, 14 anos já esta usando", "Na tribo chamamos a internet de Maracá de branco. Maraca é o instrumento que o pajé usa em rituais para enxergar e analisar o mundo inteiro...", acrescenta André, 2006 (apud BOCCHINNI, 2006, p. 32-33).

Outro caso da região amazônica, aonde existe uma ampla parceria entre entidades de governo, área privada, terceiro setor e sociedade civil, é em São Gabriel da Cachoeira (AM) com $95 \%$ da população de origem indígena e possivelmente único lugar mais plurilíngüe das Américas conta com três pontos de presença. São 112 quilômetros quadrados (maior que Portugal ou Santa Catarina), onde se falam 222 línguas indígenas de quatro troncos lingüísticos diferentes (Tuoi-Guarani, Tukano oriental, Maku e Aruak). Uma das antenas do GESAC fica na Escola indígena Baniwa Coripaco Pamaáli. Por falta de energia elétrica, foi preciso adaptar células solares nos equipamentos para afazer conexão. Pamaáli, assim como a escola dos Tuyuka, adota projetos políticos e pedagógicos totalmente elaborados pelas comunidades, a partir de suas necessidades, entre elas a valorização das línguas nativas.(DIAS; LARANJEIRAS, 2005, p.13-14)

Outro ponto de presença foi instalado como telecentro, há um ano e meio, na FOIRN, que representa a 750 comunidades indígenas com 35 mil índios. É resultado de um trabalho conjunto do GESAC, da FOIRN, do Ministério de Educação e da ONG ISA- que também 
atuam na Escola Pamaáli-, e da multinacional IBM.

No telecentro da FOIRN, as comunidades elaboram documentos, fazem edição de texto e pesquisas. São seis computadores IBM que apóiam tarefas didáticas de professores e alunos, e sempre pelo menos em duas línguas, e que acessam a Internet para divulgação de produtos - artesanato, principalmente - , elaboração e divulgação de boletins informativos e para a busca de financiadores e novos parceiros.

A equipe do ISA na região é formada por antropólogos, demógrafo, pedagoga, agrônomos, engenheiro de pesca, administrador, entre outros. Segundo o administrador da FOIRN, Roberto Barão, a iniciativa é uma grande conquista dos povos indígenas, "que precisam se comunicar com o mundo, ter reconhecimento e se atualizar". O terceiro ponto na região esta com a Fundação Banco do Brasil. (DIAS ; LARANJEIRAS, 2005, p.13-14)

Iniciativas como essa não estão presentes apenas na região amazônica, em Araracruz, no Espírito Santo, duas aldeias já têm laboratórios de informática cedidos pelo Banco do Brasil e gerenciados pelo Centro de Práticas Sociais, Educacionais e de Cidadania (CEPEC). Os índios das tribos Caieiras Velha e Pau-Brasil, 2 mil em total, usam Windows. "Tentamos o Linux , mas não deu certo, o banco só nos forneceu uma versão espanhol" disse Jose dos Santos do CEPEC. Aqui Araracruz é uma exceção, pois nos demais projetos o software livre é dominante. (BOCCHINI, 2006, p. 33)

Existe outro caso de inclusão digital indígena, entre a equipe do Massachusetts Institute of Technology (MIT), alunos e professores da Escola Politécnica da USP e da Fundação Bradesco (rede de Centros de Inclusão Digital da Fundação e portal indígena) para aplicar tecnologias sociais - rápidas fáceis e baratas-em comunidades de Canuanã, nas margens do rio Javaés, no Tocantins.

A parceria da Fundação com o MIT começou no inicio de 2005, com a primeira visita

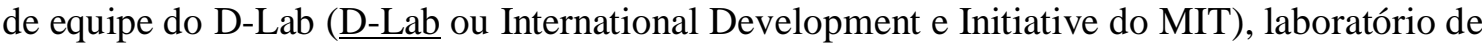
desenvolvimento do instituto, para diagnosticar problemas locais. A principal preocupação de Stepanhie Dalquist, coordenadora da missão do D-Lab, foi com a apropriação dos projetos pelas comunidades, depois que os pesquisadores se forem ela indicou "Não podemos resolver as dificuldades locais só com tecnologia”.

Uma das comunidades atendidas é a reserva indígena da Ilha do Bananal, a aldeia Canuanã, com 400 índios e a maior das 11 que reúnem 1,4 mil Javaé na ilha. Desde janeiro de 2005, conta com o Centro de Inclusão digital (CID) equipado com dez computadores e web. Dois professores índios, Olavo Lohaware Javaé e Josivaldo Fudiuare, foram capacitados 
por alunos da Fundação Bradesco para serem monitores. E um professor de informática da fundação dá cursos de iniciação aos aplicativos cedidos pela Microsoft.

\section{Conclusões}

A inclusão digital indígena constitui uma das mais recentes políticas públicas para a "inclusão" deste segmento social, no âmbito do conhecimento, os quais historicamente foram mais objetos passivos de políticas indigenistas assimilacionistas e tutelares, em vez de ser participes ativos na solução dos seus problemas.

A inclusão digital destinada à população indígena é mais do tipo restrita, isto é, aquela ligada à disponibilidade de equipamentos tecnológicos, o consumo de recursos e informações e a capacitação de pessoas para o uso de computadores. Contudo este último aspecto é algo também muito demandado pelos indígenas, pois quase não existe.

Existem alguns casos destacados de comunidades indígenas que já começaram a utilizar os recursos tecnológicos com objetivos autônomos, como se relatou em alguns casos neste documento.

A participação do setor privado, influenciada pela denominada responsabilidade social, é outro fato destacado, que pode ser distinguido a nível empresarial, o que demonstra que a inclusão digital, já não é só uma medida pública.

A sociedade civil, o terceiro setor (ONGs, Fundações, etc), e as parcerias entre o setor público e privado é outra situação, mais escassa.

Algumas etnias se começaram a organizar para ser participes da chamada Sociedade da Informação, porém em geral hão tido um papel passivo, sendo receptores de medidas governamentais ou privadas, o que poderia influir na demora na expansão de programas de inclusão digital para eles.

\section{Referências Bibliográficas}

AQUINO, Miriam, DIAS, Lia R. Casa Brasil: um modelo para reduzir a exclusão. ARede: tecnologia para a inclusão social, ano 1, n.1, p.9-13. 2005.

BOCCHINI, Lino. As aldeias dentro da rede. ARede, ano 1, n.111, p.32-35,fev . 2006. 
COSTA, Leonardo. Inclusão digital uma alternativa para o social? Análise de projetos realizados em Salvador. In: ENCONTRO LATINO-AMERICANO DE ECONOMIA APLICADA, ECONOMIA POLÍTICA DE INFORMAÇÃO, COMUNICAÇÃO E CULTURA, 5., 9-11, nov. 2005. Bahía: Anais ... Salvador: Faculdade da Bahia, 2005. 1 CROM.

DIAS R., Lia. GESAC: revisão adia expansão do programa. ARede. ano 1, ago. 2005.

.Em defesa do Gesac. ARede. ano 1, set. 2005.

GALVÃO B., Sofia. A inclusão digital: programas governamentais e o profissional da informação, reflexões. Inclusão social. v.1, n.2, p.23-30, abr/set. 2006.

LAIPELT, Rita. [et al...] Biblioteca comunitaria e telecentro: unidos na busca da inclusão social. In: CONGRESSO BRASILEIRO DE BIBLIOTECONOMIA, DOCUMENTAÇÃO e CIÊNCIA DA INFORMAÇÃO , 21, 17-22, jul. 2005. Curitiba: [Anais do] Curitiba: [s,n.], 2005.

LÉVY, Pierre. Cibercultura. São Paulo: Editora 34, 1999.

MINISTERIO DE PLANEJAMENTO, ORÇAMENTO E GESTÃO, Secretaria de Logística e Tecnologia de Informação. Guia Livre: Referencia de migração para software livre do governo federal.Versão Ipiranga, 2004. On line.2004

NERI, Marcelo Cortes. Mapa da exclusão digital. Rìo de Janeiro: FGV/IBRE, CPS, 2003.

RONDELLI, Elizabeth. Quatro passos para inclusão digital. I-coletiva. [S.l. S.n.], 2003.Disponível em: <http://www.comunicacao.pro.br/setepontos/5/4passos.htm>. Acesso em: 29. jun. 2008

SILVEIRA, Sergio A. da.; CASSINO, João (Orgs.). Software livre e inclusão digital. São Paulo: Conrad editora do Brasil 2003.

SORJ, Bernardo. Brasil@ povo.com: a luta contra a desigualdade na sociedade da informação. Rio de Janeiro: Jorge Zahar Ed.; UNESCO, 2003.

YOUNG, R. A inclusão digital e as metas do milênio. Inclusão social. v.1, n.2, p.96-99, abr/set. 2006. 